\title{
Pengaruh Lingkungan Kerja dan Disiplin Terhadap Kinerja Pegawai pada Bagian Administrasi Pemerintahan Umum Sekretariat Daerah Pematangsiantar
}

\author{
Eka Pratiwi Septania Parapat \\ Sekolah Tinggi Akuntansi dan Manajemen \\ Indonesia \\ ekapsparapat@gmail.com
}

\author{
Wiranto Sinaga \\ Sekolah Tinggi Akuntansi dan Manajemen \\ Indonesia \\ wirantosinaga1910@gmail.com
}

\author{
Eve Ida \\ Sekolah Tinggi Akuntansi dan Manajemen Indonesia \\ eveidamalau@gmail.com
}

\begin{abstract}
An employee who has a good and high performance can support the achievement of organizational goals. Human resource issues become the spotlight and foundation of the organization. The formulation of the problem in this study is the work environment and discipline of cooperation on the performance of employees in the General Government Administration of the Pematangsiantar City Secretariat. This study aims to determine the effect of work environment and work discipline on employee performance in the General Government Administration of Pematangsiantar City Secretariat. The research design used by the author is field research, where the research is carried out in the General Government Administration of the Pematangsiantar City Secretariat, the population is the employees of the Pematangsiantar City Secretariat General Government Administration. The sampling technique used a saturated sample using the entire population as a research sample, amounting to 37 employees. The data analysis technique uses multiple regression, hypothesis testing, coefficient of determination. The results showed that the work environment and work discipline have a positive effect on the performance of employees in the General Government Administration of the Pematangsiantar City Secretariat
\end{abstract}

Keywords: Work Environment, Work Discipline, Employee Performance

\section{A. PENDAHULUAN}

Bagian Administrasi Pemerintahan

Umum Sekretariat Daerah Kota Pematangsiantar merupakan sebuah organisasi perangkat daerah yang berupaya memberikan pelayanan prima guna terwujudnya dengan baik pelaksanaan tugas penyelenggaraan pemerintah, administrasi pemerintahan serta terpenuhinya pelayanan administratif kepada seluruh perangkat daerah dengan mengimplementasikan cara kerja yang cepat, efesien dan transparan terhadap kebutuhan perangkat daerah. Kinerja pegawai pada Bagian Administrasi Pemerintahan Umum Sekretariat Daerah Kota Pematangsiantar diatur dalam Peraturan tentang tata kelola kinerja pegawai[1].

Kinerja merupakan salah satu hal yang perlu diperhatikan dalam sebuah perusahaan serta menentukan berhasil tidaknya tujuan organisasi yang telah ditetapkan. Kinerja merupakan hasil pekerjaa yang dicapai 
seseorang berdasarkan persyaratan-persyaratan pekerjaan. Suatu pekerjaan mempunyai syarat tertentu untuk dapat dilakukan dalam mencapai tujuan tertentu. Dengan adanya kinerja maka tingkat pencapaian hasil akan terlihat sehingga akan diketahui seberapa jauh hasil dari tugas dan wewenang yang diberikan dapat dilaksanakan dengan maksimal.

Kinerja pegawai Bagian Administrasi Pemerintahan Umum Sekretariat Daerah Kota Pematangsiantar dapat diukur berdasarkan Peraturan Pemerintah Nomor 46 Tahun 2011 terdiri dari dua dimensi, pertama yaitu Sasaran Kerja Pegawai (SKP). Kedua yaitu Perilaku Kerja (PK).Adapun fenomena dimensi kinerja pegawai pada Bagian Administrasi Pemerintahan Umum Sekretariat Daerah Kota Pematangsiantar.

Adapun faktor yang mempengaruhi kinerja pegawai Pada Bagian Administrasi Pemerintahan Umum Sekretariat Daerah Kota Pematangsiantar adalah lingkungan kerja. Lingkungan kerja adalah segala aspek kerja, psikologis kerja, peraturan kerja dan kenyamanan diantara sesama rekan kerja yang dapat mempengaruhi kinerja pegawai[2]. Lingkungan kerja yang kondusif memberikan rasa aman dan memungkinkan para pegawai untuk dapat berkerja secara optimal [3].

Lingkungan kerja merupakan salah satu faktor penting yang dapat mempengaruhi kinerja pegawai yang terdiri dari lingkungan kerja fisik dan lingkungan kerja non fisik. Dimensi lingkungan kerja fisik dapat dilihat dari bangunan tempat kerja. Di samping faktor lingkungan, faktor disiplin kerja juga dapat mempengaruhi kinerja pegawai. Disiplin juga sebagai suatu alat yang digunakan para manajer untuk berkomunikasi dengan pegawai agar mereka brsedia mengubah suatu peilaku[4]. Dimensi disiplin kerja pada Administrasi Pemerintahan Umum Sekretariat Kota Pematangsiantar antara lain adalah mejalankan kewajiban dan menjauhi larangan.

Rumusan masalah dalam penelitian ini adalah bagaimanapengaruh lingkungan kerja dan disiplin kerjaterhadap kinerja pegawai pada Bagian Administrasi Pemerintahan Umum Sekretariat Daerah Kota Pematangsiantar Maka tujuan penelitian ini adalah untuk mengetahui pengaruh lingkungan kerja dan disiplin kerjaterhadap kinerja pegawai pada Bagian Administrasi Pemerintahan Umum Sekretariat Daerah Kota Pematangsiantar.

\section{URAIAN TEORITIS Manajemen}

Secara umum manajemen adalah individu atau sekelompok individu yang menerima tanggung jawab untuk menjalankan organisasi. Para pemimpin merencanakan, mengatur, mengarahkan, dan mengawasi semua kegiatan penting dari organisasi.

Manajemen adalah suatuproses pengaturan dan pemanfaatan sumber daya yang dimilikiorganisasi melalui kerjasama para anggota untuk mencapaitujuan organisasi secara efektif dan efesien[5].Sangat penting bagi suatu organisasi untuk memiliki manajemen yang baik, dengan adanya manajemen suatu organisasi dapat melakukan perencanaan yang efektif dan efisien.Fungsi manajemen ditetapkan agar tujuan dari organisasi tersebut dapat tercapai dengan efektif dan efisien, manajemen juga berfungsi untuk mengatur permasalahan-permasalahan yang terjadi didalam organisasi.

\section{Manajemen Manajemen Sumber Daya Manusia}

Sumber daya manusia merupakan salah satu sumber daya yang memiliki peranan penting dalam pencapaian tujuan suatu organisasi. Karena dalam pencapaian tujuan organisasi. Manajer yang mampu melihat sumber daya manusia sebagai asset yang harus dikelola dengan baik adalah manajer yang berhasil. Karena tanpa adanya sumber daya manusia yang baik, kegiatan operasional suatu organisasi atau perusahaan tidak dapat berjalan dengan baik.

Manajemen sumber daya manusia dapat didefinisikan sebagai suatu proses perencanaan, pengorganisasian, penyusunan staf, penggerakan, dan pengawasan terhadap pengadaan, pengembangan, pemberian kompensasi, pengintegrasian, pemeliharaan, 
dan pemisahan tenaga kerja untuk mencapai tujuan organisasi[6].Manajemen sumber daya manusia digunakan oleh organisasi sebagai fungsi untuk mengetahui perkembanganperkembangan didalam oraganisasi tersebut dan juga memperhatikan hubungan kerja setiap pegawai dengan baik

\section{Lingkungan Kerja}

Lingkungan kerja merupakan salah satu hal yang sangat mempengaruhi kinerja para pegawai, oleh sebab itu lingkungan kerja harus sangat diperhatikan oleh organisasi. Lingkungan kerja merupakan keseluruhan alat perkakas dan bahan yang dihadapi, lingkungan sekitarnya dimana seseorang bekerja, metode kerjanya, serta pengaturan kerjanya baik sebagai perorangan maupun sebagai kelompok[7].

Lingkungan kerja merupakan suatu kondisi organisasi yang ada disekitar pegawai berupa tempat kerja, peraturan organisasi, rekan kerja dan pengaturan kerjanya. lingkungan kerja adalah segala sesuatu yang ada disekitar para pegawai didalam melakukan pekerjaannya yang mempengaruhi para pegawai didalam melaksanakan pekerjaannya baik lingkungan yangsecara fisik maupun nonfisik.

Faktor-faktor yang mempengaruhi lingkungan kerja maka penulis mengambil kesimpulan, fator-faktor yang mempengaruhi lingkungan kerja adalah satu kondsi atau keadaan dari lingkungan kerja yang mendukung para pegawai untuk dapat memaksimalkan kinerjanya, seperti faktor kamanan, ruang gerak, faktor cahaya, kebisingan, tata warna, musik, dan sirkulasi udara didalam lingkungan kerja tersebut.

\section{Disiplin Kerja}

Didalam organisasi disiplin sangat lah penting, terutama disiplin yang diterapkan kepada para pegawai didalam organisasi tersebut. Karena dengan adanya disiplin didalam suatu organisasi akan memberikan suatu peraturan akan sikap yang harus di terapkan para pegawainya didalam melaksanakan tugas dan tanggung jawabnya untuk mencapai tujuan dari organisasi. Dan dengan adanya disiplin didalam organisasi akan membantu dalam mengontrol sikap dan tindakan para pegawai didalam melaksanakan pekerjaannya..

Dicipline is management action of enforce organizationstandards". Disiplin kerja merupakan suatu pelaksanaan manajemen untuk memperteguh pedoman-pedoman organisasi[2]. Disiplin kerja dapat dilihat sebagai sesuatu yang besar manfaatnya, baik bagi kepentingan organisasi maupun bagi para karyawan. Sebab ketidakdisiplinan dan kedisiplinan dapat menjadi panutan bagi orang lain.

Disiplin sangat diperlukan bagi untuk diri sendiri maupun organisasi, dengan adanya disiplin kita akan dapat mengatur sikap yang kita miliki dalam melaksanakan tugas dan tanggung jawab yang kita miliki[8]. Tujuan dari disiplin kerja adalah untuk dapat mengatur sikap dan tindakan para pegawai didalam melancarkan tercapainya tujuan dari organisasi dengan tertib dan teratur.

\section{Kinerja Pegawai}

Penilaian kinerja yang dilakukan suatu perusahaan merupakan suatu proses mengevaluasi pelaksanaan kerja individu, kegiatan ini dapat memperbaiki keputusankeputusan personalia dan memberikan umpan balik kepada para pegawai tentang pelaksanaan dan memberikan umpan balik kepada para pegawai tentang pelaksanaan kerja mereka, serta memungkinkan perusahaan mengetahui seberapa baik seorang pegawai jika dibandingkan dengan standar-standar yang berlaku diorganisasi

Kinerja adalah hasil pekerjaan yang dicapai seseorang berdasarkan persyaratanpersyaratan pekerjaan (job requirement) [6]. Pengertian kinerja (prestasi kerja) adalah hasil kerja secara kualitas dan kuantitas yang dicapai oleh seorang pegawai dalam melaksanakan tugasnya sesuai dengan tanggung jawab yang diberikan kepadanya.

Banyak faktor yang mempengaruhi kinerja pegawai baik itu secaraindividual ataupun kemampuan maupun usaha yang 
dicurahkan juga dukungan yang diterima karyawan.Penilaian kinerja karyawan dilakukan untuk meminimalkan perilaku yang tidak semestinya diinginkan melalui umpan balik hasil kinerja karyawan pada waktunya serta penghargaan, baik yang bersifat intrinsik maupun ekstrinsik. Penilaian kerja karyawan merupakan faktor penting untuk suksesnya manajemen kinerja. Sistem tersebut penting karena mencerminkan secaralangsung rencana strategik organisasi

Hipotesis merupakan jawaban sementara terhadap rumusan masalah penelitian, di mana rumusan masalah penelitian telah dinyatakan dalam bentuk pertanyaan[9]. Adapun hipotesis yang diajukan sebagai berikut:

1. Lingkungan Kerja berpengaruh terhadap kinerja pegawai.

2. Disiplin Kerja berpengaruh terhadap kinerja pegawai

3. Lingkungan Kerja dan Disiplin kerja berpengaruh terhadap kinerja pegawai

Kerangka Konseptual dalam penelitian ini adalah:

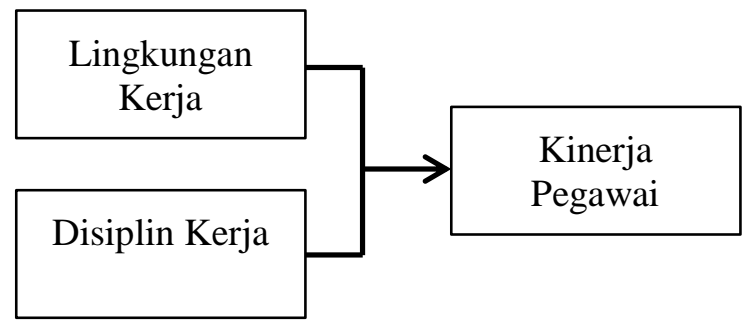

\section{Gambar 1. Kerangka Konseptual}

\section{METODE PENELITIAN \\ Jenis Penelitian}

Pendekatan asosiatif digunakan dalam penelitian ini. Desain penelitian yang digunakan penulis adalah Penelitian lapangan (Field Research). Data yang digunakan penelitian ini menggunakan data primer dengan mengumpulkan data dan wawancara kepada pegawai pada Administrasi Pemerintahan Umum Kota Pematangsiantar.
Tempat penelitian dilakukan pada Administrasi Pemerintahan Umum Kota Pematangsiantar.

\section{Ruang Lingkup}

Ruang lingkup penelitian ini membahas mengenai lingkungan kerja, disiplin dan kinerja pegawai pada Administrasi Pemerintahan Umum Sekretariat Daerah Kota Pematangsiantar. Dimana yang menjadi dimensi lingkungan kerja yaitulingkungan kerja fisik dan lingkungan kerja non fisik. Dimensi disiplin adalah menaati peraturan dan menjauhi larangan. Sedangkan dimensi kinerja pegawai adalah sasaran kinerja pegawai (SKP) dan perilaku kerja (PK) pada Administrasi Pemerintahan Umum Sekretariat Daerah Kota Pematangsiantar.

\section{Populasi dan Sampel}

Populasi yaitu pegawai Kantor BPPRD Provinsi Sumatera Utara UPT Pematangsiantar yang berjumlah 37 orang. Teknik pengambilan sampel menggunakan sampel jenuh dimana teknik penentuan sampel ini menggunakan semua anggota populasi digunakan sebagai sampel. Sampel yang digunakan dalam penelitian ini adalah sejumlah 37 orang yang berada di lingkungan Kantor Administrasi Pemerintahan Umum Kota Pematangsiantar.

\section{Prosedur}

Data kauntitatif digunakan dalam penelitian ini. Data kuantitatif diperoleh didapatkan jawaban responden mengenai harga, keputusan pembelian dan selera.

\section{Teknik Pengumpulan Data}

Teknik pengumpulan datadengan metode dokumentasi dengan cara mengumpulkan data dan informasi melalui buku-buku karangan ilmiah, referensi dan menggunakan media elektronik untuk searching.Sebelum melakukan pengumpulan data dengan kuisioner dilakukan uji intrusmen data, dengan uji validitas, dan reliabilitas.

\section{Tabel 1. Hasi Uji Validitas}

\section{Tempat Penelitian}




\begin{tabular}{|c|c|c|c|c|}
\hline Variabel & $\begin{array}{c}\text { Butir } \\
\text { Instrumen }\end{array}$ & $\begin{array}{c}\mathbf{r} \\
\text { hitung }\end{array}$ & $\begin{array}{c}\mathbf{r} \\
\text { kritis }\end{array}$ & $\begin{array}{c}\text { Hasil } \\
\text { Uji }\end{array}$ \\
\hline \multirow{10}{*}{$\begin{array}{c}\text { Lingkungan } \\
\text { Kerja (X1) }\end{array}$} & X1.1 & 0,400 & 0,3 & Valid \\
\hline & $\mathrm{X} 1.2$ & 0,378 & 0,3 & Valid \\
\hline & $\mathrm{X} 1.3$ & 0,545 & 0,3 & Valid \\
\hline & $\mathrm{X} 1.4$ & 0,691 & 0,3 & Valid \\
\hline & $\mathrm{X} 1.5$ & 0,430 & 0,3 & Valid \\
\hline & X1.6 & 0,402 & 0,3 & Valid \\
\hline & $\mathrm{X} 1.7$ & 0,604 & 0,3 & Valid \\
\hline & $\mathrm{X} 1.8$ & 0,594 & 0,3 & Valid \\
\hline & X1.9 & $\mathbf{0 , 3 3 9}$ & 0,3 & Valid \\
\hline & $\mathrm{X} 1.10$ & 0,474 & 0,3 & Valid \\
\hline \multirow{32}{*}{$\begin{array}{c}\text { Disiplin } \\
\text { Kerja (X2) }\end{array}$} & $\mathrm{X} 2.1$ & $\mathbf{0 , 6 3 0}$ & 0,3 & Valid \\
\hline & $\mathrm{X} 2.2$ & 0,677 & 0,3 & Valid \\
\hline & $\mathrm{X} 2.3$ & 0,431 & 0,3 & Valid \\
\hline & $\mathrm{X} 2.4$ & 0,679 & 0,3 & Valid \\
\hline & $\mathrm{X} 2.5$ & 0,498 & 0,3 & Valid \\
\hline & $\mathrm{X} 2.6$ & $\mathbf{0 , 4 5 0}$ & 0,3 & Valid \\
\hline & $\mathrm{X} 2.7$ & 0,567 & 0,3 & Valid \\
\hline & $\mathrm{X} 2.8$ & 0,484 & 0,3 & Valid \\
\hline & X2.9 & 0,498 & 0,3 & Valid \\
\hline & $\mathrm{X} 2.10$ & 0,523 & 0,3 & Valid \\
\hline & $\mathrm{X} 2.11$ & $\mathbf{0 , 3 8 2}$ & 0,3 & Valid \\
\hline & $\mathrm{X} 2.12$ & $\mathbf{0 , 7 9 9}$ & 0,3 & Valid \\
\hline & $\mathrm{X} 2.13$ & 0,659 & 0,3 & Valid \\
\hline & $\mathrm{X} 2.14$ & 0,337 & 0,3 & Valid \\
\hline & $\mathrm{X} 2.15$ & 0,457 & 0,3 & Valid \\
\hline & $\mathrm{X} 2.16$ & $\mathbf{0 , 3 5 0}$ & 0,3 & Valid \\
\hline & $\mathrm{X} 2.17$ & $\mathbf{0 , 4 7 7}$ & 0,3 & Valid \\
\hline & $\mathrm{X} 2.18$ & 0,645 & 0,3 & Valid \\
\hline & $\mathrm{X} 2.19$ & 0,711 & 0,3 & Valid \\
\hline & $\mathrm{X} 2.20$ & 0,682 & 0,3 & Valid \\
\hline & $\mathrm{X} 2.21$ & $\mathbf{0 , 3 5 9}$ & 0,3 & Valid \\
\hline & $\mathrm{X} 2.22$ & $\mathbf{0 , 7 4 5}$ & 0,3 & Valid \\
\hline & $\mathrm{X} 2.23$ & 0,799 & 0,3 & Valid \\
\hline & $\mathrm{X} 2.24$ & 0,683 & 0,3 & Valid \\
\hline & $\mathrm{X} 2.25$ & 0,612 & 0,3 & Valid \\
\hline & $\mathrm{X} 2.26$ & 0,724 & 0,3 & Valid \\
\hline & $\mathrm{X} 2.27$ & $\mathbf{0 , 4 3 8}$ & 0,3 & Valid \\
\hline & $\mathrm{X} 2.28$ & 0,764 & 0,3 & Valid \\
\hline & $\mathrm{X} 2.29$ & 0,723 & 0,3 & Valid \\
\hline & $\mathrm{X} 2.30$ & 0,391 & 0,3 & Valid \\
\hline & $\mathrm{X} 2.31$ & 0,361 & 0,3 & Valid \\
\hline & $\mathrm{X} 2.32$ & $\mathbf{0 , 6 7 9}$ & 0,3 & Valid \\
\hline \multirow{12}{*}{$\begin{array}{c}\text { Kinerja } \\
\text { Pegawai (Y) }\end{array}$} & Y.1 & 0,449 & 0,3 & Valid \\
\hline & Y.2 & 0,463 & 0,3 & Valid \\
\hline & Y.3 & 0,564 & 0,3 & Valid \\
\hline & Y.4 & 0,666 & 0,3 & Valid \\
\hline & Y.5 & 0,346 & 0,3 & Valid \\
\hline & Y.6 & $\mathbf{0 , 5 8 1}$ & 0,3 & Valid \\
\hline & Y.7 & $\mathbf{0 , 4 5 0}$ & 0,3 & Valid \\
\hline & Y.8 & 0,426 & 0,3 & Valid \\
\hline & Y.9 & 0,398 & 0,3 & Valid \\
\hline & Y.10 & 0,421 & 0,3 & Valid \\
\hline & Y.11 & $\mathbf{0 , 3 2 9}$ & 0,3 & Valid \\
\hline & Y.12 & $\mathbf{0 , 4 7 8}$ & 0,3 & Valid \\
\hline
\end{tabular}

\begin{tabular}{|c|c|c|c|c|}
\hline Variabel & $\begin{array}{c}\text { Butir } \\
\text { Instrumen }\end{array}$ & $\begin{array}{c}\text { r } \\
\text { hitung }\end{array}$ & $\begin{array}{c}\mathbf{r} \\
\text { kritis }\end{array}$ & $\begin{array}{c}\text { Hasil } \\
\text { Uji }\end{array}$ \\
\hline \multirow{6}{*}{} & Y.13 & $\mathbf{0 , 3 2 3}$ & 0,3 & Valid \\
\cline { 2 - 5 } & Y.14 & $\mathbf{0 , 4 8 7}$ & 0,3 & Valid \\
\cline { 2 - 5 } & Y.15 & $\mathbf{0 , 3 5 2}$ & 0,3 & Valid \\
\cline { 2 - 5 } & Y.16 & $\mathbf{0 , 4 1 1}$ & 0,3 & Valid \\
\cline { 2 - 5 } & Y.17 & $\mathbf{0 , 5 5 1}$ & 0,3 & Valid \\
\cline { 2 - 5 } & Y.18 & $\mathbf{0 , 6 2 2}$ & 0,3 & Valid \\
\cline { 2 - 5 } & Y.19 & $\mathbf{0 , 4 9 5}$ & 0,3 & Valid \\
\cline { 2 - 5 } & Y.20 & $\mathbf{0 , 4 2 1}$ & 0,3 & Valid \\
\hline
\end{tabular}

Sumber: Pengolahan Data (2020)

Berdasarkan tabel di atas diketahui semua indikator variabel dalam penelitian ini adalah valid.

Tabel 2. Hasil Uji Realibilitas

\begin{tabular}{ccc}
\hline $\begin{array}{c}\text { Cronbach's } \\
\text { Alpha }\end{array}$ & N of item & Hasil Uji \\
\hline $\mathbf{0 , 9 5 3}$ & 10 & Reliabel \\
$\mathbf{0 , 9 5 2}$ & 32 & Reliabel \\
$\mathbf{0 , 9 5 4}$ & 20 & Reliabel \\
\hline
\end{tabular}

Sumber: Pengolahan Data (2020)

Dari tabel di atas disimpulkan indikator variabel dalam penelitian ini adalah reliabel.

\section{Teknik Analisis Data}

Teknik analisis data ialah uji kualitas data, uji Asumsi Klasik, analisis regresi linear berganda, uji hipotesis, dan koefesien determinasi.

\section{HASIL DAN PEMBAHASAN}

\section{HASIL}

\section{Uji Asumsi Klasik}

Hasil uji normalitas menggunakan uji Kolmogorov-Smirnov, sebagai berikut:

\section{Tabel. 3 Hasil Uji Normalitas}

\begin{tabular}{|lr|r|}
\hline & & \multicolumn{1}{|c|}{ Total } \\
\hline$N$ &, 0000000 & 37 \\
Normal & 1,30908517 & 227,29 \\
Parameters $^{a, b}$ &, 061 & 20,327 \\
Most Extreme &, 050 &, 096 \\
Differences &,- 061 &, 077 \\
Kolmogorov-Smirnov $Z$ & &,- 096 \\
Asymp. Sig. (2-tailed) & &, 372 \\
A. Test distibution is Normal &, 999 \\
\hline
\end{tabular}

a. Test distribution is Normal. 
b. Calculated from data.

Sumber: Pengolahan Data (2020)

Berdasarkan tabel di atas dapat dilihat unstandardized Residual, 0,999> 0,05. Maka dpat disimpulkan seluruh variabel berdistribusi normal.

\section{Uji Multikolineritas}

Uji multikolineritas menggunakan Varince Inflation Factor (VIF), sebagai berikut:

Tabel 4. Hasil Uji Multikolineritas Coefficients $^{\mathbf{a}}$

\begin{tabular}{|ll|r|r|}
\hline \multirow{2}{*}{ Model } & \multicolumn{2}{|c|}{ Collinearity Statistics } \\
\cline { 2 - 3 } & Tolerance & \multicolumn{1}{c|}{ VIF } \\
\hline \multirow{2}{*}{1 (Constant) } & & \\
& Lingkungan Kerja &, 989 & $\mathbf{1 , 0 1 1}$ \\
& Disiplin Kerja &, 989 & $\mathbf{1 , 0 1 1}$ \\
\hline
\end{tabular}

a. Dependent Variable: Keputusan Pembelian Sumber: Pengolahan Data (2020)

Dari tabel diatas diperoleh nilai VIF untuk seluruh variabel $<10$, artinya tidak terjadi gejala multikolineritas.

\section{Uji Heterokedasitas}

Uji heterokedasitas diuji menggunakan metode grafik, dengan hasil sebagai berikut:

\section{Scatterplot}

Debendent Variable: $Y$

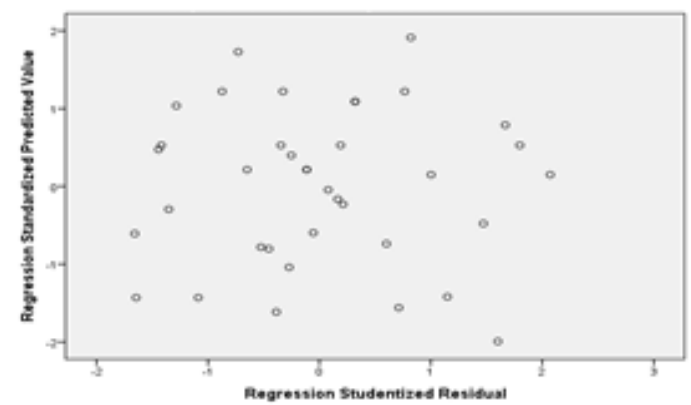

Sumber: Pengolahan Data (2020)

Gambar 2. Grafik Scatreeplot

Dari gambar grafik scatterplot diatas terlihat menyebar secara acak, maka dinyatakan tidak terjadi gejala heterokedastisitas.

\section{Uji Regresi Linaer Berganda}

Analisis regresi linier berganda bertujuan untuk menganalisis pengaruh disiplin kerja, kerja sama terhadap kinerja pegawai. Hasil pengujian sebagai berikut:

\section{Tabel 5. Hasil Regresi Linear Berganda} Coefficients $^{a}$

\begin{tabular}{|c|c|c|c|}
\hline \multirow[t]{2}{*}{ Model } & \multicolumn{2}{|c|}{$\begin{array}{c}\text { Unstandardized } \\
\text { Coefficients }\end{array}$} & $\begin{array}{l}\text { Standardized } \\
\text { Coefficients }\end{array}$ \\
\hline & $\boldsymbol{B}$ & $\begin{array}{c}\text { Std. } \\
\text { Error }\end{array}$ & Beta \\
\hline (Constant) & 18,622 & 8,49 & \\
\hline $\begin{array}{ll}\text { Lingkungan } \\
\text { Kerja (X1) }\end{array}$ & ,604 & ,234 & ,016 \\
\hline $\begin{array}{l}\text { Disiplin Kerja } \\
\text { (X2) }\end{array}$ & ,287 & ,089 & ,003 \\
\hline
\end{tabular}

Sumber: Pengolahan Data (2020)

Berdasarkan tabel di atas, diperoleh model persamaan regresi, sebagai berikut:

$\hat{\mathrm{Y}}=18,622+0,604 \mathrm{X}_{1}+0,287 \mathrm{X}_{2}$,

Persamaan regresi diperoleh hasil terdapat pengaruh positif antara lingkungan kerja $\left(\mathrm{X}_{1}\right)$ dan disiplin kerja $\left(\mathrm{X}_{2}\right)$ terhadap kinerja pegawai (Y) pada Bagian Administrasi Pemerintahan Umum Sekretariat Daerah Kota Pematangsiantar.

\section{Uji Hipotesis}

Uji Parsial (Uji t)

Untuk mengetahui pengaruh masingmasing variabel digunakan uji t. Hasil uji t, sebagai berikut:

Tabel 7. Hasil Uji t

Coefficients $^{\mathrm{a}}$

\begin{tabular}{|l|r|r|}
\hline Model & \multicolumn{1}{|c|}{ Sig. } \\
\hline (Constant) & 2,192 &, 038 \\
$\quad$ Lingkungan kerja & $\mathbf{2 , 5 8 6}$ &, $\mathbf{0 1 6}$ \\
1 (X1) & \\
$\quad$ Disiplin kerja ( & $\mathbf{3 , 2 3 4}$ &, $\mathbf{0 0 3}$ \\
X2)
\end{tabular}

a. Dependent Variable: Y

Sumber: Pengolahan Data (2020)

Berdasarkan hasil uji $\mathrm{t}$, diperoleh nilai $t_{\text {hitung }}$ pada variabel $\mathrm{X}_{1}$ (lingkungan kerja) sebesar 2,586 $>\mathrm{t}_{\text {tabel }}$ dengan $\mathrm{df}=2,030(\mathrm{df}=37$ $3=35$ ) atau taraf signifikan $0,016<\alpha 0,05$, maka 
$\mathrm{H}_{0}$ ditolak, artinya lingkungan kerja berpengaruh positif dan signifikan terhadap kinerja pegawai pada Bagian Administrasi Pemerintahan Umum Sekretariat Daerah Kota Pematangsiantar.

Nilai $t_{\text {hitung }}$ pada variabel $\mathrm{X}_{2}$ (disiplin kerja) sebesar 3,234> dari $t_{\text {tabel }}$ dengan $\mathrm{df}=$ 2,030 (df=37-3=35)sebesar 2,030 atau taraf signifikan $0,003<\alpha 0,05$, maka $\mathrm{H}_{0}$ ditolak, artinya disiplin kerja berpengaruh positif dan signifikan terhadap kinerja pegawai pada Bagian Administrasi Pemerintahan Umum Sekretariat Daerah Kota Pematangsiantar.

\section{Uji Simultan (Uji F)}

UjiF menunjukkanapakahsemua variabelindependenataubebas dimasukkandalammodel,yangmempunyaipeng aruhsecara bersama-sama terhadap variabel dependen.Hasil uji F pada tabel di bawah ini:

\section{Tabel 8. Hasil Uji F}

\begin{tabular}{|l|c|c|}
\multicolumn{3}{|c|}{ ANOVA $^{\mathbf{a}}$} \\
\hline Model & F & Sig. \\
\hline \multicolumn{1}{|c|}{ Regression } & $\mathbf{2 2 , 0 2 3}$ & $\mathbf{, 0 0 0}^{\mathbf{b}}$ \\
1 Residual & & \\
$\quad$ Total & & \\
\hline
\end{tabular}

a. Dependent Variable: Y

b. Predictors: (Constant), X2, X1

Sumber: Pengolahan Data (2020)

Berdasarkan tabel di atas diperoleh nilai Fhitung sebesar 22,023 $>\mathrm{F}_{\text {tabel }}$ nilai $\mathrm{F}$ tabel sebesar 3,27 $(\mathrm{df}=37-2=35)$, atau dengan signifikan $0,000<\alpha 0,05$, makaH $_{0}$ ditolak, artinya lingkungan kerja dan disiplin kerja berpengaruh positif dan signifikan terhadap kinerja pegawai pada Bagian Administrasi Pemerintahan Umum Sekretariat Daerah Kota Pematangsiantar.

\section{Koefesien Determinasi}

Koefisien determinasi ini berfungsi untuk mengetahui persentasebesarnya pengaruh variabel independen dan variabel dependenyaitudengan mengkuadratkan koefisienyangditemukan.

Untukmengetahuisejauhmana kontribusiataupersentase pengaruh disiplin kerja dan kerja samaterhadap kinerjapegawai makadapat diketahu melalui uji determinasi sebagai berikut:

\section{Tabel 9.Koefisien Determinasi}

Model Summary ${ }^{\mathrm{b}}$

\begin{tabular}{|l|r|r|r|r|}
\hline Model & $\mathrm{R}$ & $\begin{array}{c}\mathrm{R} \\
\text { Square }\end{array}$ & $\begin{array}{c}\text { Adjusted R } \\
\text { Square }\end{array}$ & $\begin{array}{l}\text { Std. Error of the } \\
\text { Estimate }\end{array}$ \\
\hline 1 & $\mathbf{, 7 9 9}^{\mathrm{a}}$ & $\mathbf{, 6 3 8}$ &, 609 & 4,191 \\
\hline
\end{tabular}

a. Predictors: (Constant), X2, X1

b. Dependent Variable: Y

Sumber: Pengolahan Data (2020)

Berdasarkan tabel di atas, diperoleh hasil dari nilai koefisien determinasinya (Adjusted $\mathrm{R}$ Square) sebesar 0,609 yang berarti 60,9\% tinggi rendahnya kinerja pegawai dapat dijelaskan oleh ingkungan kerja dan disiplin kerja sedangkan sisanya $39,1 \%$ dipengaruhi oleh faktor lain yang tidak dimasukkan dalam penelitian ini seperti prestasi kerja, loyalitas, kepercayaan, pengembangan karir, kemampuan intelektual, gaya kepemimpinan, pelatihan, kepuasan kerja pendidikan, etos kerja, budaya organisasi.

\section{PEMBAHASAN}

Lingkungan kerja adalah segala sesuatu yang ada disekitar para pegawai didalam melakukan pekerjaannya yang mempengaruhi para pegawai didalam melaksanakan pekerjaannya baik lingkungan yang secara fisik maupun non-fisik.Berdasarkan uji regresi linear berganda diperoleh bahwa lingkungan kerja dan disiplin kerja berpengaruh positif terhadap kinerja pengawai pada Bagian Administrasi Pemerintahan Umum Sekretariat Daerah Kota Pematangsiantar, artinya peningkatakan pada lingkungan kerja dan disiplin kerja yang dilakukan akan meningkatkan kinerja pegawai. Hasil uji hipotesis untuk uji t untuk variabel lingkunagn kerja diperoleh bahwa disiplin kerja berpengaruh signifikan terhadap kinerja pegawai pada Bagian Administrasi Pemerintahan Umum Sekretariat Daerah Kota Pematangsiantar, hal ini sejalan dengan penelitian [10], [3], [11], mengatakan bahwa, lingkungan kerja merupakan segala sesuatu yang ada di sekitar karyawan yang dapat 
memengaruhi dirinya dalam menjalankan tugas-tugas yang sudah diembankan padanya, dan hal ini berbanding terbalik dengan penelitian yang dilakukan [8]. Lingkungan kerja yang kurang mendapat perhatian akan membawa dampak negatif dan menurunkan tingkat kinerja, hal ini disebabkan karyawan dalam melaksanakan tugas mengalami gangguan, untuk meningkatkan disiplin kerja sebaiknya membuat lingkungan kerja yang nyaman dan kondusif serta hubungan di antara sesama pegawai pun baik, maka karyawan akan cenderung bekerja lebih baik, dengan mengganti peralatan yang tidak layak pakai sepert komputer, printer, infocus, meja kerja, kursi kerja, lemari kantor dengan peralatan yang baru agar lebih mendukung pegawai dalam meningkatkan pekerjaannya Hal ini menunjukkan bahwa kinerja pegawai dapat ditingkatkan dengan lingkungan kerja yang baik.

Disiplin kerja berpengaruh positif dan signifikan terhadap kinerja pegawai pada Bagian Administrasi Pemerintahan Umum Kota Pematangsiantar, hal ini sesuai dengan pendapat ahli[12], dan penelitian yang dilakukan [13], [4],[14] bahwa apabila Disiplin kerja yang baik yakni mencerminkan besarnya rasa tanggung jawab seseorang terhadap tugas-tugas yang diberikan kepadanya. Hal tersebut dapat mendorong timbulnya peningkatan kinerja serta tercapainya tujuan perusahaan.

Untuk meningkatkan disiplin kerja atasan perlu memberikan pegawai pemahaman lebih melalui seminar tentang UUD 1945 dan menjadwalkan pegawai untuk bergatian membaca UUD 1945 pada saat upacara bendera, serta pegawai yang tidak setia kepada UUD 1945 diberikan hukuman disiplin berat seperti pemindahan dalam rangka penurunan jabatan yang lebih rendah dan pembebasan dari jabatan hal ini dilakukan supaya pegawai bisa lebih setia dan taat terhadap UUD 1945.

Untuk uji F diperoleh terdapat pengaruh yang positif dan signifikan antara variabel lingkungan kerja dan disiplin berpengaruh positif dan signifikan terhadap kinerja pegawai pada Bagian Administrasi Pemerintahan Umum Kota Pematangsiantar, hal ini berarti lingkungan kerja yang baik didukung dengan tingkat kedisiplinan yang tinggi akan menghasilkan kinerja karyawan yang baik, sebaliknya pada lingkungan kerja kurang baik dan tingkat kedisiplinan yang rendah akan menghasilkan kinerja karyawan yang kurang baik pula hasil, hal ini sejalan dengan pnelitian yang dilakukan [8]Koefesien determinasi (Adjusted R Square) sebesar 0,609 yang berarti $60,9 \%$ tinggi rendahnya kinerja pegawai dapat dijelaskan oleh ingkungan kerja dan disiplin kerja sedangkan sisanya 39,1\% dipengaruhi oleh faktor lain yang tidak dimasukkan dalam penelitian ini seperti prestasi kerja, loyalitas, kepercayaan, pengembangan karir, kemampuan intelektual, gaya kepemimpinan, pelatihan, kepuasan kerja pendidikan, etos kerja, budaya organisasi. Untuk meningkatkan kinerja pegawai atasan perlu menjadi contoh yang baik bagi pegawai lainnya serta memberikan motivasi kepada pegawai seperti memberikan dorongan kepada pegawai untuk terus belajar dan berkembang untuk meningkatkan pencapaian kerja.

\section{KESIMPULAN DAN SARAN}

\section{Kesimpulan}

Dari hasil uji regresi linear berganda diperoleh lingkungan kerja dan disiplin kerja berpengaruh positif terhadap kinerja pengawai pada Bagian Administrasi Pemerintahan Umum Kota Pematangsiantar. Hasil uji hipotesis uji t, diperoleh lignkungan kerja berpengaruh signifikan terhadap kinerja pegawai pada Bagian Administrasi Pemerintahan Umum Kota Pematangsiantar, dan disiplin kerja berpengaruh signifikan terhadap kinerja pegawai pada pada Bagian Administrasi Pemerintahan Umum Kota Pematangsiantar. Hasil uji hipotesis uji F diperoleh lingkungan kerja dan disiplin kerja berpengaruh signifikan terhadapkinerja pegawai dan kerja sama berpengaruh signifikan terhadap kinerja pegawai pada Bagian Administrasi Pemerintahan Umum Kota Pematangsiantar. Nilai koefisien determinasinya (Adjusted R Square) sebesar 0,609 yang berarti $60,9 \%$ tinggi rendahnya 
kinerja pegawai dapat dijelaskan oleh ingkungan kerja dan disiplin kerja sedangkan sisanya $39,1 \%$ dipengaruhi oleh faktor lain.

\section{Saran}

Berdasarkan kesimpulan dan hasil evaluasi penelitian yang telah dilakukan, maka penulis memberikan beberapa saran untuk meningkatkan lingkungan kerja sebaiknya membuat lingkungan kerja yang nyaman dan kondusif serta hubungan di antara sesama pegawai pun baik, maka karyawan akan cenderung bekerja lebih baik, dengan mengganti peralatan yang tidak layak pakai sepert komputer, printer, infocus, meja kerja, kursi kerja, lemari kantor dengan peralatan yang baru agar lebih mendukung pegawai dalam meningkatkan pekerjaannya

Untuk meningkatkan disiplin kerja atasan perlu memberikan pegawai pemahaman lebih melalui seminar tentang UUD 1945 dan menjadwalkan pegawai untuk bergatian membaca UUD 1945 pada saat upacara bendera, serta pegawai yang tidak setia kepada UUD 1945 diberikan hukuman disiplin berat. Untuk meningkatkan kinerja pegawai atasan perlu menjadi contoh yang baik bagi pegawai lainnya serta memberikan motivasi kepada pegawai seperti memberikan dorongan kepada pegawai untuk terus belajar dan berkembang untuk meningkatkan pencapaian kerja.

\section{DAFTAR PUSTAKA}

[1] Peraturan Pemerintah Republik Indonesia No 46, "Tentang Penilaian Prestasi Kerja Pegawai Negeri Sipil.," 2011.

[2] A. P. M. dan A. Waris, "Effect of Training, Competence and Discipline on Employee Performance in Company (Case Study in PT. Asuransi Bangun Askrida)," Procedia - Soc. Behav. Sci., vol. 211, pp. 1240-1251, 2015, doi: 10.1016/j.sbspro.2015.11.165.

[3] N. L. Pioh and H. N. Tawas, "Pengaruh Kompensasi dan Lingkungan Kerja terhadap Kepuasan Kerja dan Kinerja Pegawai (Studi Pada PNS Di Kantor Kecamatan Sonder Kabupaten
Minahasa )," J. EMBA, vol. 4, no. 2, pp. 838-848, 2016.

A. Pangarso and P. I. Susanti, "Pengaruh Disiplin Kerja Terhadap Kinerja Pegawai Di Biro Pelayanan Sosial Dasar Sekretariat Daerah Provinsi Jawa Barat," J. Manaj. Teor. dan Ter. J. Theory Appl. Manag., vol. 9, no. 2, pp. 145-160, 2016, doi: 10.20473/jmtt.v9i2.3019.

[5] C. Wijaya and M. Rifa'i, Dasat Dasar Manajemen, Mengoptimalkan Pengelolaan Organisasi Secara Efektif dan Efesien. Medan: Perdana Publishing, 2016.

[6] W. Bangun, Manajemen Sumber Daya Manusia. Jakarta: Erlangga, 2012.

[7] Sedarmayanti, Manajemen Sumber Daya Manusia. Bandung: Refika Aditama, 2010.

[8] S. Hartanto and E. Widjanti, "PENGARUH DISIPLIN DAN LINGKUNGAN KERJA TERHADAP KINERJA PEGAWAI DENGAN KEPEMIMPINAN SEBAGAI VARIABEL MODERASI," J. Manaj. Sumberd. Mns., vol. 5, no. 1, pp. 34-41, 2011.

[9] Sugiyono, Metodologi Penelitian Bisnis. Bandung: Alfabeta, 2010.

[10] A. E. Murti and R. Nurgraheni, "ANALISIS PENGARUH KOMPENSASI KERJA, DISIPLIN KERJA, DAN LINGKUNGAN KERJA FISIK TERHADAP KINERJA PEGAWAI (Studi pada CV. Metalindo Manunggal Karsa)," Diponegoro $J$. Manag., vol. 4, no. 1, pp. 1-14, 2014.

[11] Kristiadi, Asmu'i, and M. H. Arifin, "Pengaruh Kepemimpinan Transformasional, Lingkungan Kerja Fisik dan Disiplin Kerja terhadap Kinerja Pegawai pada Perusahaan Daerah Air Minum ( PDAM ) Puruk Cahu," J. Bisnis dan Pembang., vol. 8, no. 2, pp. 24-38, 2019.

[12] S. P. Robbins and A. J. Timothy, Perilaku Organisasi, Sebelas. Jakarta: Salemba Empat, 2008. 
[13] M. Hatta, S. Musnadi, and Mahdani, "Pengaruh Gaya Kepemimpinan, Kerjasama Tim dan Kompensasi Terhadap Kepuasan Kerja Serta Dampaknya Pada Kinerja Karyawan PT. PLN (Persero) Wilayah Aceh," Bisnis Unsyiah, vol. 1, no. 1, pp. 70-80, 2017.

[14] D. Untari, "Pengaruh Displin Kerja Terhadap Kinerja Pegawai Pada PT. KIE Indonesia," Cano Ekon., vol. 7, no. 1, pp. 1-15, 2018. 